\title{
Prevalence of household food poverty in South Africa: results from a large, nationally representative survey
}

\author{
Donald Rose and Karen E Charlton* \\ Nutrition and Dietetics Unit, Department of Medicine, University of Cape Town, Observatory 7925, Cape Town, \\ South Africa
}

Submitted 15 June 2001: Accepted 16 November 2001

\begin{abstract}
Objectives: Household food insecurity is a major determinant of undernutrition, yet there is little information on its prevalence in the South African population. This paper assesses household food insecurity in South Africa using a quantitative and objective measure, known as food poverty, and provides prevalence estimates by geographic area and socio-economic condition.

Design: Secondary data analysis combining two sources: Statistics South Africa's household-based 1995 Income and Expenditure Survey; and the University of Port Elizabeth's Household Subsistence Level series, a nationally-conducted, marketbased survey.

Setting: South Africa.

Subjects: A nationally representative sample of the entire country - stratified by race, province, and urban and non-urban areas - consisting of 28704 households.

Results: A household is defined to be in food poverty when monthly food spending is less than the cost of a nutritionally adequate very low-cost diet. The prevalence of food poverty in South Africa in 1995 was 43\%. Food poverty rates were highest among households headed by Africans, followed by coloureds, Indians and whites. Higher food poverty rates were found with decreasing income, increasing household size, and among households in rural areas or those headed by females.

Conclusions: The widespread nature of household food insecurity in South Africa is documented here. Prevalence rates by geographic and socio-economic breakdown provide the means for targeting of nutritional interventions and for monitoring progress in this field. The corroboration of these findings with both internal validation measures and external sources suggests that food poverty is a useful, objective measure of household food insecurity.
\end{abstract}

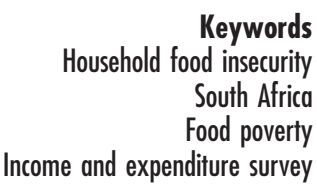

Food supplies at a national level in South Africa are adequate to feed the entire population ${ }^{1,2}$; however, a number of studies have revealed evidence of undernutrition among certain segments of the population ${ }^{3}$. Marginal vitamin A status, iron-deficiency anaemia and stunting, a symptom of chronic energy deficiency, all represent serious public health problems for the country ${ }^{4}$. These problems of undernutrition develop when nutrient intakes are insufficient to meet nutrient requirements.

Inadequate nutrient intakes are often caused by household food insecurity, defined as a household's lack of access to amounts of food of the right quality to satisfy the dietary needs of all its members throughout the year ${ }^{5}$. The role of food insecurity as an underlying determinant of inadequate dietary intakes has been elucidated in various causal frameworks on malnutrition. Figure 1 shows an example of one that is adapted from the wellknown United Nations Children's Fund (UNICEF) framework ${ }^{6}$.
The South African Department of Health's Integrated Nutrition Programme includes a number of interventions to address problems of undernutrition, most of which function by improving household food security ${ }^{5}$. Food fortification programmes operate by improving the nutritional quality of food available to households. Community gardens are designed to improve the household's access to certain types of foods. Even individual food transfer programmes, such as primary school feeding, improve household food security by augmenting the total amount of food available to household members.

The key role of household food insecurity - in the aetiology of undernutrition and as a point of intervention for its improvement - highlights the importance of being able to measure the phenomenon. Valid population-level diagnostic tools, if they were available in South Africa, could be used to improve the targeting of nutrition interventions and to monitor progress over time in meeting food security and nutrition objectives. 


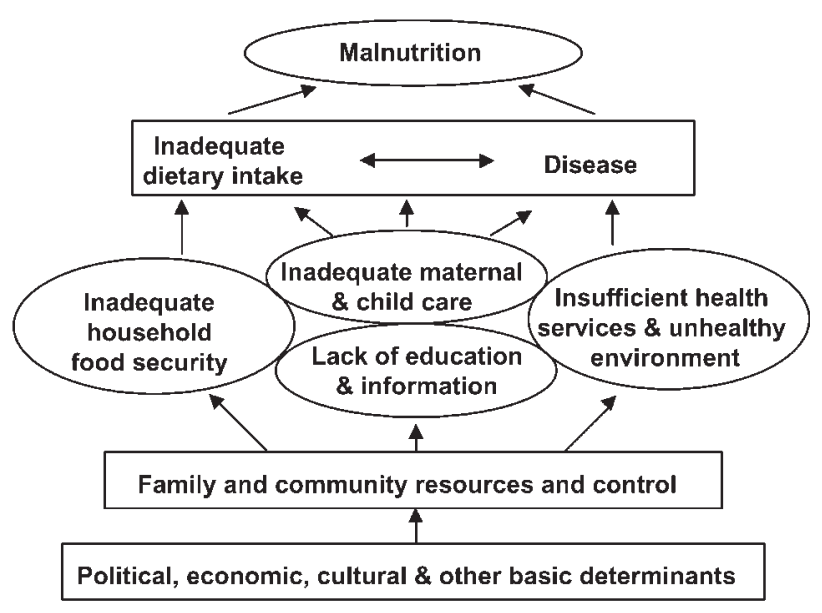

Fig. 1 Causal framework outlining immediate, underlying and basic determinants of malnutrition

Unfortunately, only recently have tools been developed to measure hunger and food insecurity at the household level. For the most part, these tools, developed in the United States $^{7-10}$, are based on a battery of questions, a number of which rely on qualitative and subjective assessments. For example, some questions address whether respondents are worried that their food will run out, or whether adults in the household eat less than they feel they should. While such questions may be appropriate in a country of excess, where food insecurity is largely a hidden phenomenon, exclusive reliance on them in the South African context is of concern.

In this paper, a quantitative, objective method to measure household food security in South Africa is described. Based on the concept of food poverty, this method allows for the ongoing monitoring of food insecurity with nationally representative data and provides policymakers with information that is useful for targeting resources to areas of greatest need.

\section{Methods}

A household is defined here to be in food poverty when the amount of money it spends on food is inadequate to purchase a basic, nutritionally adequate diet. Assessment of food poverty requires two types of information empirical data on household food spending and normative data on the content and cost of a basic diet.

Here, this issue is explored in the South African context with secondary data analyses of two surveys: the 1995 Income and Expenditure Survey (IES), which supplied information on household food spending; and the Household Subsistence Level (HSL) series from the Institute for Planning Research at the University of Port Elizabeth (UPE), which supplied information on the cost of a basic subsistence diet.

The IES was conducted by Statistics South Africa in October of 1995 (concurrently with the 1995 October
Household Survey) to determine expenditure patterns of South African households ${ }^{11}$. Among other purposes, data from the IES are used to form the basket of consumer goods and services used in the calculation of the Consumer Price Index.

Unlike previous income and expenditure surveys in South Africa, which are conducted every five years, the 1995 version covered all areas of the country including metropolitan, urban and rural areas. The sample stratified by race, province, urban and non-urban area consisted of 30000 households, of which 28704 provided usable information on food purchases. The 1991 population census was used as a frame for drawing the sample and included estimates of the size of the population in the formerly independent TBVC (TranskeiBophuthatswana-Venda-Ciskei) states. Statistical weights supplied with the 1995 IES were used for all results presented in this report. Additional details regarding sampling procedures have been published previously $^{11}$.

Monthly spending, in Rands, on 124 foods was obtained from face-to-face interviews with the household head. The value of gifts in the form of food was also reported by the respondent and included with data on monthly spending. Information on the quantities consumed of home-grown foods and livestock was also collected in another part of the survey, which included an additional 22 items, such as grains, milk, eggs, fruits, vegetables and meats. Consumption of home-produced foods was converted to a monetary value using median sales prices from the IES database. Total monthly spending on food was calculated for each household by summing up its expenditures on purchased foods and the monetary value of the food consumed from home production.

The UPE HSL series is an ongoing, biannual market survey of the costs of food, clothing and other household necessities in 24 urban centres throughout South Africa ${ }^{12}$. The food items chosen for pricing in each of these centres are based on the 1993 food ration scales developed by the previous South African Department of National Health and Population Development. These scales - designed at three cost levels - provide the minimum quantities of a selection of food items needed to meet the nutrient requirements for different age-gender groups. Table 1 displays the items in the very low-cost scales for selected age-gender groups. Although HSL obtains prices for food items in both the very low-cost and low-cost scales, the former was used here due to the interest in developing a food poverty measure. The HSL series presents the total cost of a subsistence level of food (that is, the sum of the costs of the individual food items in the food ration scales) for nine different age-gender groups in each of the locations where food price data were collected. Based on the data from the 24 locations, provincial averages were developed here for the cost of a basic subsistence diet for each of these age-gender groups. 
Table 1 Very low-cost monthly food ration scales used in the Household Subsistence Level ${ }^{12}$ for selected age and gender groups (quantities in grams)

\begin{tabular}{|c|c|c|c|c|c|}
\hline Food item & $\begin{array}{l}\text { Adult male } \\
\text { (19+ years) }\end{array}$ & $\begin{array}{l}\text { Adult female } \\
\text { (19+ years) }\end{array}$ & $\begin{array}{c}\text { Child } \\
\text { (1-3 years) }\end{array}$ & $\begin{array}{c}\text { Child } \\
\text { (4-6 years) }\end{array}$ & $\begin{array}{c}\text { Child } \\
\text { (7-10 years) }\end{array}$ \\
\hline Skimmed milk powder & 1200 & 1200 & 1200 & 1200 & 1200 \\
\hline Meat (red \& chicken) & 795 & 795 & 245 & 389 & 577 \\
\hline Fish (pilchards) & 397 & 397 & 123 & 195 & 289 \\
\hline Eggs $(1$ egg $=50 \mathrm{~g})$ & 650 & 650 & 650 & 650 & 650 \\
\hline Fresh vegetables & 9000 & 9000 & 3600 & 5550 & 7650 \\
\hline Fresh fruit & 1083 & 1083 & 823 & 823 & 1083 \\
\hline Margarine & 600 & 450 & 300 & 450 & 450 \\
\hline Cooking oil (ml) & 606 & 606 & 260 & 433 & 606 \\
\hline Brown bread $(800 \mathrm{~g})$ & 8400 & 4200 & 1650 & 2100 & 3150 \\
\hline Maize meal, samp & 7200 & 5400 & 3600 & 5400 & 5400 \\
\hline Sugar, jam & 2100 & 1200 & 900 & 1050 & 1200 \\
\hline Peanut butter & 433 & 433 & 260 & 260 & 260 \\
\hline Legumes (beans \& peas) & 390 & 390 & 65 & 130 & 130 \\
\hline Coffee \& tea & 217 & 217 & 0 & 0 & 130 \\
\hline Salt & 130 & 130 & 65 & 65 & 130 \\
\hline Dry spices, condiments, e.g. pepper, curry & 44 & 44 & 22 & 22 & 44 \\
\hline Liquid spices, condiments, e.g. vinegar (ml) & 87 & 87 & 44 & 44 & 87 \\
\hline
\end{tabular}

This information from the HSL was merged with household composition data from the IES. This allowed for calculation of the cost of a basic subsistence diet for each household in the IES, based on the age-gender distribution of its members and the province in which it was located. The food poverty line is defined here as the cost of a nutritionally adequate subsistence diet for a household; that is, households spending less are considered to be in food poverty. This varies by province, reflecting variations in food prices, and by household composition, reflecting differing amounts of foods needed by individuals of different ages or gender.

Household food spending as a percentage of the food poverty line was calculated as the amount the household spent on food for a month divided by the cost of a basic subsistence diet for that household, and multiplied by 100 to convert to percentage terms. A dichotomous food poverty variable was created to indicate when household spending fell below this food poverty line.

\section{Results}

On average, South African households spent $170 \%$ of the cost of a nutritionally adequate basic diet in October 1995. The distribution of this food-spending variable is shown in Fig. 2. Households in which food expenditure was less than $100 \%$ of the cost of this basic diet - those to the left of the solid bar in Fig. 2 - are considered to be in food poverty. They make up $42.6 \%$ of the population. As can be seen from the figure, the distribution of food spending is skewed to the left, an asymmetry typical of economic variables such as income and expenditures.

Table 2 displays the breakdown of food spending and food poverty rates by various demographic and socioeconomic characteristics. Households in Gauteng had the highest average food spending $-250 \%$ of the food poverty line - whereas households in the Northern Cape had the lowest spending at $118 \%$ of the food poverty line. Although, on average, households in all the provinces spend greater than the cost of a basic subsistence diet, this statistic can be misleading, since it does not give information on the percentage of households below the food poverty line. The last column in Table 2 provides information on the food poverty rate; that is, the percentage of households spending below the cost of a basic subsistence diet. The highest rates of food poverty were seen in the Northern Cape, followed by the Northern Province and the Free State, whereas the lowest rates were seen in Gauteng and the Western Cape. The food poverty rate in rural areas of South Africa was 62\%, compared with $27 \%$ in urban areas.

Households were ranked by per capita income and divided into 10 equal groups or deciles. Food poverty rates were averaged for each decile and are displayed in Fig. 3. As expected, food poverty was inversely related to per capita income. The opposite relationship was seen with household size. Households of seven or more persons had the highest rate of food poverty, 78\%, while one-to-two person households had the lowest rate, 17\%. Over half of female-headed households were in food poverty,

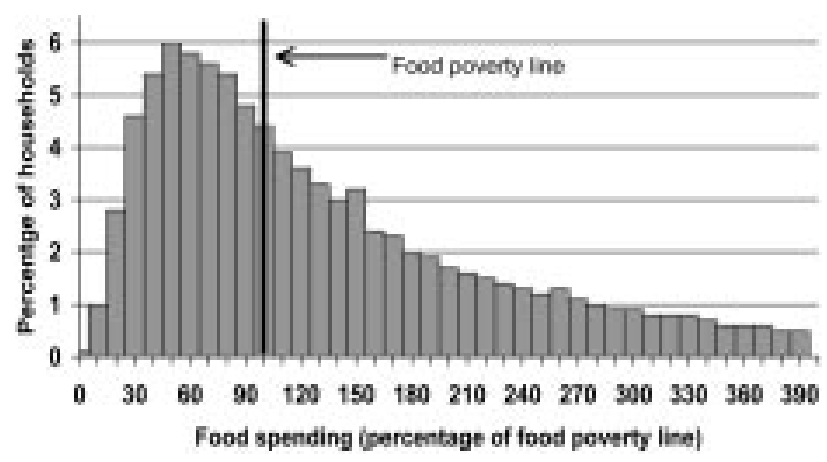

Fig. 2 Distribution of food spending in South African households, October 1995 
Table 2 Mean household food spending and food poverty rates, by demographic and socio-economic characteristics

\begin{tabular}{|c|c|c|c|c|}
\hline & \multirow[b]{2}{*}{$n$} & \multicolumn{2}{|c|}{ 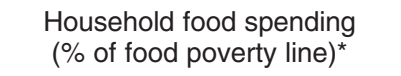 } & \multirow{2}{*}{$\begin{array}{l}\text { Households } \\
\text { in food } \\
\text { poverty† (\%) }\end{array}$} \\
\hline & & Mean & Standard error & \\
\hline All households & 28704 & 170.2 & 0.9 & 42.6 \\
\hline \multicolumn{5}{|l|}{ Province } \\
\hline Western Cape & 3198 & 212.5 & 3.2 & 23.9 \\
\hline Eastern Cape & 3155 & 155.2 & 3.2 & 48.2 \\
\hline Northern Cape & 3487 & 117.8 & 2.3 & 61.5 \\
\hline Free State & 2655 & 136.9 & 3.2 & 55.1 \\
\hline KwaZulu Natal & 5254 & 162.1 & 2.0 & 43.7 \\
\hline North West & 2481 & 137.9 & 2.7 & 52.1 \\
\hline Gauteng & 3394 & 250.4 & 2.5 & 20.6 \\
\hline Mpumalanga & 2470 & 129.8 & 2.8 & 53.7 \\
\hline Northern Province & 2610 & 122.0 & 2.0 & 57.1 \\
\hline \multicolumn{5}{|l|}{ Urbanisation } \\
\hline Rural & 12164 & 109.0 & 0.9 & 62.1 \\
\hline Urban & 16540 & 218.5 & 1.4 & 27.3 \\
\hline \multicolumn{5}{|c|}{ Race of household head } \\
\hline African & 18635 & 119.1 & 0.7 & 55.6 \\
\hline Coloured & 3716 & 160.7 & 2.5 & 34.9 \\
\hline Indian & 1019 & 260.3 & 6.1 & 9.0 \\
\hline White & 5334 & 348.3 & 2.7 & 3.1 \\
\hline \multicolumn{5}{|l|}{ Sex of household head } \\
\hline Male & 19777 & 182.4 & 1.2 & 38.6 \\
\hline Female & 8927 & 143.2 & 1.5 & 51.5 \\
\hline \multicolumn{5}{|c|}{ Household size (persons) } \\
\hline $1-2$ & 7486 & 264.3 & 2.4 & 17.4 \\
\hline $3-4$ & 9123 & 183.8 & 1.5 & 33.7 \\
\hline $5-6$ & 6819 & 121.1 & 1.2 & 54.3 \\
\hline $7+$ & 5276 & 78.6 & 0.8 & 77.8 \\
\hline
\end{tabular}

* The food poverty line is defined here as the cost of a basic subsistence diet for a household; that is, the sum, over all of its members, of the costs of the very low-cost food ration scales (see Table 1). This varies by household because of differences in household composition and because of provincial food price differences.

† Households are in food poverty when their monthly spending on food, plus the value of food gifts received, plus the value of own-produced food, is less than their food poverty line.

compared with $39 \%$ of male-headed households. Figure 4 shows food poverty rates for households of different size and gender of the household head. Higher rates of food poverty were seen among female-headed households at all household sizes, except for one-person households. The food poverty rate was highest among households headed by Africans at 56\%, and lowest among households headed by whites at $3 \%$.

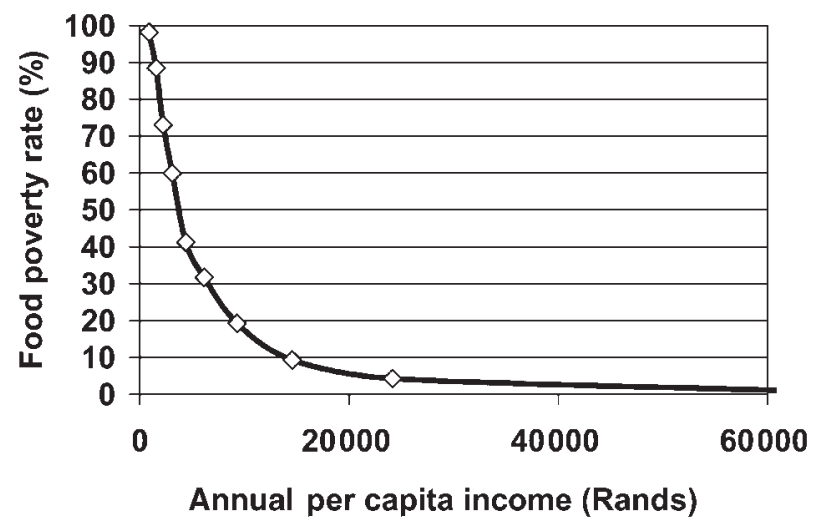

Fig. 3 Food poverty rates by decile of per capita income

\section{Discussion}

The aim of this paper was to develop an objective tool for measuring food insecurity in South Africa and to estimate national and provincial prevalence rates for the condition, as well as to identify determinants of food insecurity. The results reported here show that $43 \%$ of households in South Africa experienced food poverty in October 1995. Food poverty rates were highest among households headed by Africans, followed by coloureds, Indians and whites. Higher food poverty rates were found with decreasing income, increasing household size, among households headed by females and among households living in rural areas.

These patterns were confirmed using two other methods of internal validation. In one method, instead of using the Household Subsistence Level series, the cost of a subsistence diet was obtained using the Minimum Living Levels (MLL), a series conducted by the University of South Africa's Bureau of Market Research. The MLL market survey is also conducted twice annually but differs from the HSL series in a number of ways, including the specific food items and amounts that make up the subsistence diet and the locations where market surveys 


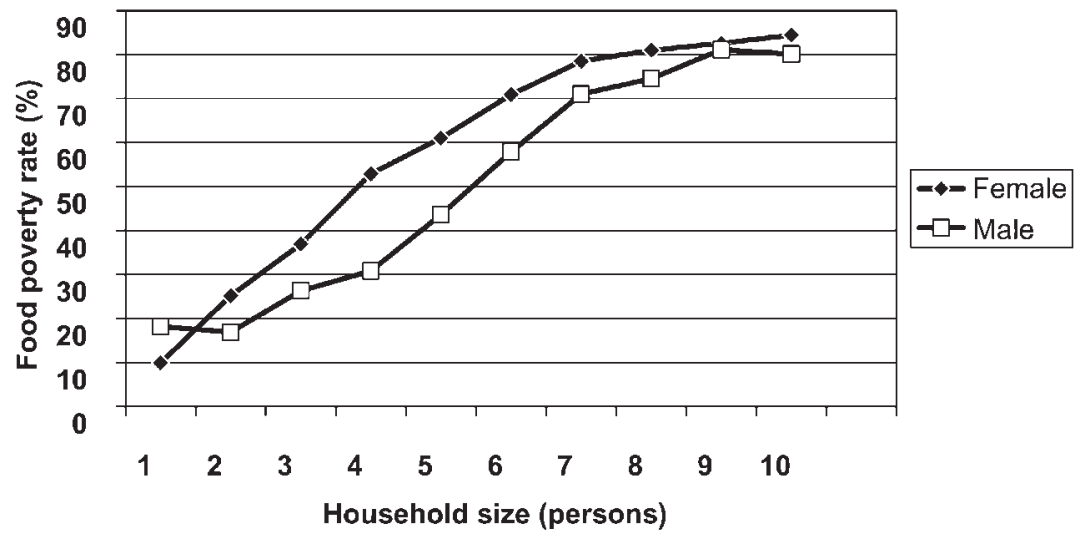

Fig. 4 Food poverty rates by household size and gender of household head

are conducted to price these food items ${ }^{13}$. Although the absolute rates of food poverty were higher with the MLL data - 50\% nation-wide - all of the patterns described in the previous paragraph remained the same.

In a second validation method, the food energy available to each household in the IES was calculated and compared with each household's total energy needs. When the energy available to a household, through its food purchases and consumption of home-produced foods, was less than the sum of its members' Recommended Dietary Allowances for energy ${ }^{14}$, that household was considered to be food insecure. Rates of food insecurity, using this available energy measure, were then compared with our original food poverty measure. Almost all of the relative patterns were the same, although the absolute levels of food insecurity were higher. In this case, the nation-wide rate was 55\%. Because of cooking and other losses, household food availability estimates are usually greater than actual individual intakes, so the true food insecurity rate based on this measure may in fact be higher.

Poor households often cope with poverty by adopting a very monotonous diet that may nevertheless address their basic nutritional needs. The basic ration diet used in this study is in fact quite varied with fish, meat, eggs and other foods. We felt it was important to assess food poverty throughout the country using one acceptable standard. Should resources be targeted to the areas of need outlined in this paper, such decisions would be based on a common country-wide benchmark. Clearly, different types of diet would yield different rates of food poverty. For example, using a more costly food ration scale - one based on fluid milk, more meat and chicken and less maize - the national food poverty rate was even higher, 59.8\%. Using a lower-cost diet based on just maize and beans as a reference, the food poverty rate would be lower.

Larger households may be able to economise on their food budgets and thus have lower per person food costs. We experimented with this possibility by incorporating the economy of scale factors used in the US Thrifty Food Plan, a tool analogous to the South African food ration scales. Documentation accompanying this Plan suggests that total food costs for households with less than four members should be increased by specified percentages, while they should be decreased for larger households ${ }^{15}$. On a national level we found South African food poverty rates to be almost identical (42.5 instead of 42.6\%) when these factors were included. Because overall results were not affected by this and because of a lack of research on which economy of scale factors should be used in South Africa, for clarity of interpretation we have presented all results without use of such economy of scale factors. However, results from future research on economy of scale factors in South Africa could easily be incorporated into our methods.

The findings reported here are consistent with other studies on income and poverty in South Africa. The skewed nature of the food spending distribution in Fig. 2 indicates that the bulk of the population spends relatively little on food, while a much smaller percentage, represented by the stretched right-hand tail, spends quite a lot. The vast differential between some rich households and the poor has been seen in the analysis of income data from South Africa, which has one of the highest inequality rates in the world ${ }^{16}$. As reported here for food poverty, Leibbrandt and Woolard found that income poverty rates were highest among households headed by Africans, followed by coloureds, Indian and whites ${ }^{17}$. Their work also demonstrated higher income poverty rates in rural areas and among female-headed households ${ }^{17,18}$.

The findings are also consistent with other nutrition and food security research conducted in South Africa. The 1999 National Food Consumption Survey of children aged 1-9 years found that stunting rates, as measured by height-forage, were highest in the Northern Cape, the same province with the highest rate of food poverty identified in the present study ${ }^{19}$. The lowest stunting rates were found in Gauteng, KwaZulu Natal and the Western Cape, provinces that also had the lowest rates of food poverty, albeit in a slightly different ordering. The 1999 survey also employed a qualitative, subjective food security instrument, 
analogous to those developed in the United States. Based on this instrument, provincial rates of household food insecurity ranged from 48 to $91 \%^{20}$. These rates are much higher than those that are based on the food poverty measure used here, which ranged from 21 to 61\%.

As with all datasets, there are limitations to the Income and Expenditure Survey. First, this measure of household food security cannot consider problems of intra-household distribution, since the IES does not have individuallevel data on consumption. Creation of a household measure of food security is not a replacement for information on individual intakes, but rather an asset in targeting which types of household are likely to contain individuals with problems. Households exhibiting food insecurity are very likely to have individuals with nutrient inadequacies.

Second, there may be some imprecision in the recall of monthly food expenditures. Given that there are over 28000 observations, a small degree of imprecision should not appreciably affect confidence in the food poverty measures, in a statistical sense, since the standard errors are so small. While the degree of imprecision may vary across the income distribution, we do not believe there was a systematic bias. Analytical experience with the US Nation-wide Food Consumption Surveys has shown that recalls of overall food spending underestimate an item-byitem valuation of foods reported in a weekly food record, but other comparisons of a recall approach with a day-byday recording of food expenditures do not ${ }^{21}$. The IES is not directly comparable to these studies, since it used a hybrid approach in which recall information was obtained, but on an item-by-item basis. Further research in consumer economics is needed to fully understand the issues of precision, bias and accuracy in the recall of expenditures.

A third possible limitation concerns the use of the HSL market survey, which is conducted in urban areas. Since most of the items in the food ration scale are commercially produced and distributed, prices in outlying rural areas would likely be higher than those reported in the HSL. If true, the higher cost of a food ration scale in rural areas would imply that an even greater percentage of rural households would have fallen below the food poverty line had we used rural prices. Thus, by not doing this, we underestimated the rural food poverty rate. However, rural households have more opportunities for substituting lower-cost home-produced foods than do urban households and would be able to meet their nutrient needs in a more cost-effective way than is outlined in the fixed food ration scale used here. Rural households in some areas may also be able to collect wild foods or receive transfers of food from local support networks. To the extent that these opportunities were not accounted for, it implies that our rural rates were overestimated, an effect that dampens the underestimation of rural rates due to the use of a fixed food ration scale based on cheaper urban prices. Clearly, as reported in Table 2 , the food poverty rate is very high in rural areas, even if we must only consider it approximate.

This paper has presented a quantitative and objective way of measuring household food insecurity in South Africa. The technique takes advantage of a large nationally representative survey - the Income and Expenditure Survey - that is conducted every five years. The continual nature of the survey allows for ongoing monitoring of the food security condition in South Africa. IES was conducted in October, which is considered to be a mid-point during the year in terms of consumption. To the extent that seasonality may be an important determinant of food security in some parts of rural South Africa, it will be important to repeat this monitoring tool at the same time of the year in the future.

The very large sample size of the IES allows for targeting of interventions based on needs at the provincial level. This work can be a useful complement to smaller-scale approaches that operate at the district level or below. For example, the Household Economy Approach (HEA), pioneered by Save the Children Fund, uses rapid appraisal techniques to develop diagnoses of the food security and livelihood situation of local communities ${ }^{22}$. Background rates of food insecurity at the provincial, urbanisation, racial and economic group level, from techniques outlined in this paper, can provide a useful starting point for this local level approach. In a complementary manner, the local-level information, developed from an approach such as the HEA, provides important detail needed for subprovincial targeting of nutrition interventions and ongoing monitoring of the food security situation.

Future research in this area would benefit from work on an updated version of the IES as well as on other nationally representative databases, such as the National Food Consumption Survey, which incorporates qualitative measures of food insecurity ${ }^{20}$. The development of nation-wide monitoring tools for food security can become an important component of efforts to improve nutrition in South Africa. Given the high rates of food insecurity reported here, these efforts will need to be substantial.

\section{Acknowledgements}

The authors would like to acknowledge the support of the South African Medical Research Council, which funded Dr Rose's work with the University of Cape Town through a Visiting Scientist Grant. We also acknowledge the assistance of the University of Cape Town's Southern Africa Labour Development Research Unit in providing access to the 1995 Income and Expenditure Data. The authors appreciate the helpful insights of three anonymous reviewers.

\section{References}

1 Steyn NP, Robertson HL, Mekuria M, Labadarios D. House- 
hold food security - what health professionals should know. S. Afr. Med. J. 1998; 88: 75-9.

2 Steyn NP, Abercrombie R, Labadarios D. Food security - an update for health professionals. S. Afr.J. Clin. Nutr. 2001; 14: 98-102.

3 Vorster HH, Oosthuizen WO, Jerling JC, Veldman FJ, Burger HM. The Nutritional Status of South Africans: A Review of the Literature from 1975-1996. Durban: Health Systems Trust, 1997.

4 South African Vitamin A Consultative Group. Anthropometric, vitamin A, iron, and immunisation coverage status in children aged 6-71 months in South Africa, 1994. S. Afr. Med.J. 1996; 86: 354-7.

5 Department of Health. Integrated Nutrition Programme for South Africa: Broad Guidelines for Implementation. Draft Document No. 5. Pretoria: Department of Health, 1998.

6 United Nations Children's Fund (UNICEF). Strategy for Improved Nutrition of Women and Children in Developing Countries. New York: UNICEF, 1990.

7 Radimer KL, Olson CM, Campbell CC. Development of indicators to assess hunger. J. Nutr. 1990; 120: 1544-8.

8 Wehler CA, Scott RI, Anderson JJ. The Community Childhood Hunger Identification Project: a model of domestic hunger - demonstration project in Seattle, Washington. J. Nutr. Educ. 1992; 24: 29S-35S.

9 Briefel RR, Woteki CE. Development of food sufficiency questions for the third National Health and Nutrition Examination Survey. J. Nutr. Educ. 1992; 24: 24S-8S.

10 Andrews M, Bickel G, Carlson S. Household food security in the United States in 1995: results from the food security measurement project. Fam. Econ. Nutr. Rev. 1998; 11: $17-28$.

11 Central Statistical Service. Living in South Africa - Selected Findings of the 1995 October Household Survey. Pretoria: Central Statistical Service, 1996.

12 Potgieter JF. The Household Subsistence Level in the Major Urban Centres of the Republic of South Africa. Fact Paper No. 100. Port Elizabeth: Institute for Planning Research, University of Port Elizabeth, 1995.
13 Martins JH, Maritz ME. Minimum and Supplemented Living Levels in the Main and Other Selected Urban Areas of the RSA, August 1995. Research Report No. 225. Pretoria: Bureau of Market Research, University of South Africa, 1995.

14 Food and Nutrition Board, National Research Council. Recommended Dietary Allowances, 10th ed. Washington, DC: National Academy Press, 1989.

15 United States Department of Agriculture (USDA), Center for Nutrition Policy and Promotion. Official USDA Food Plans: Cost of Food at Home, Four Levels, US Average, July, 2001. Alexandria: USDA, 2001

16 May J, Woolard I, Klasen S. The nature and measurement of poverty and inequality. In: May J, ed. Poverty and Inequality in South Africa: Meeting the Challenge. Cape Town: David Phillip Publishers, 2000.

17 Leibbrandt M, Woolard I. Household Incomes, Poverty and Inequality in a Multivariate Framework. DPRU Working Paper No. 99/31. Cape Town: Development Policy Research Unit, University of Cape Town, 1999.

18 Woolard I, Leibbrandt M. Measuring Poverty in South Africa. DPRU Working Paper No. 99/33. Cape Town: Development Policy Research Unit, University of Cape Town, 1999.

19 Labadarios D, Maunder E, Steyn N, MacIntyre U, Nel H. National Food Consumption Survey in Children Aged 1-9 Years: South Africa 1999. Report prepared for the Food Fortification Task Group. Stellenbosch: University of Stellenbosch, 2000.

20 Maunder E, Gericke G, Labadarios D, et al. The food procurement and household food security of children aged 1-9 years in South Africa: the National Food Consumption Survey, 1999. S. Afr. J. Clin. Nutr. 2000; 13: 99.

21 Oliveira V, Rose D. Food Expenditure Estimates from the 1995 CPS Food Security Supplement. How Do They Compare with the Consumer Expenditure Survey? ERS Staff Paper No. 9617. Washington, DC: USDA-ERS, 1996.

22 Seaman J, Clarke P, Boudreau T, Holt J. The Household Economy Approach: A Resource Manual for Practitioners. London: Save the Children Fund, 2000. 